\title{
A Dominant Negative Antisense Approach Targeting $\beta$-Catenin
}

\author{
Matthias Vonbrüll ${ }^{1}$ Elisabeth Riegel ${ }^{1} \cdot$ Christian Halter $^{2} \cdot$ Michaela Aigner $^{3} \cdot$ Holger Bock $^{4} \cdot$ Birgit Werner $^{5}$. \\ Thomas Lindhorst ${ }^{5} \cdot$ Thomas Czerny $^{1}{ }^{1}$
}

Published online: 9 March 2018

(c) The Author(s) 2018. This article is an open access publication

\begin{abstract}
There have been many attempts to unveil the therapeutic potential of antisense molecules during the last decade. Due to its specific role in canonical Wnt signalling, $\beta$-catenin is a potential target for an antisense-based antitumour therapy. In order to establish such a strategy with peptide nucleic acids, we developed a reporter assay for quantification of antisense effects. The luciferase-based assay detects splice blocking with high sensitivity. Using this assay, we show that the splice donor of exon 13 of $\beta$-catenin is particularly suitable for an antisense strategy, as it results in a truncated protein which lacks transactivating functions. Since the truncated proteins retain the interactions with Tcf/Lef proteins, they act in a dominant negative fashion competing with wild-type proteins and thus blocking the transcriptional activity of $\beta$-catenin. Furthermore, we show that the truncation does not interfere with binding of cadherin and $\alpha$-catenin, both essential for its function in cell adhesion. Therefore, the antisense strategy blocks Wnt signalling with high efficiency but retains other important functions of $\beta$-catenin.
\end{abstract}

Keywords Antisense $\cdot \beta$-Catenin $\cdot$ Morpholino $\cdot$ PNA $\cdot$ Wnt signalling

\section{Introduction}

In 1978 a synthetic antisense oligonucleotide was successfully used by Zamecnik and Stephensen for targeting of Rous sarcoma virus RNA within chick embryo fibroblasts [1]. Subsequently, a vast variety of new reagents were developed and tested [2], peaking in the FDA approval of Fomivirsen

Electronic supplementary material The online version of this article (https://doi.org/10.1007/s12033-018-0058-7) contains supplementary material, which is available to authorized users.

Thomas Czerny

thomas.czerny@fh-campuswien.ac.at

1 Department of Applied Life Sciences, University of Applied Sciences, FH Campus Wien, Helmut-Qualtinger-Gasse 2, 1030 Vienna, Austria

2 Department of Engineering, University of Applied Sciences, FH Campus Wien, Favoritenstrasse 226, 1100 Vienna, Austria

3 Present Address: Sandoz GmbH, Biochemiestraße 10, 6250 Kundl, Austria

4 Present Address: CAST Gründungszentrum GmbH, Wilhelm-Greil-Straße 15, 6020 Innsbruck, Austria

5 Present Address: UGISense AG, c/o Nordwind Capital GmbH, Residenzstrasse 18, 80333 Munich, Germany
[3], Pegaptanib [4] and Mipomersen [5]. The successful clinical application demonstrated the potential of antisense reagents and motivated scientists to overcome issues with solubility, degradation or cellular delivery [6].

Due to their good affinity for complementary RNA sequences, lack of interactions with natural proteins and excellent water solubility, morpholino oligos became the gold standard for antisense knock-down experiments [7, 8]. They show a characteristic structure with a 6-membered morpholine ring replacing ring sugars present within naturally occurring nucleic acids. Furthermore, negatively charged phosphate linkages of DNA and RNA have been replaced by phosphorodiamidate intersubunit linkages [7].

In year 1991 peptide nucleic acids (PNAs) were developed by Nielsen and colleagues [9]. PNAs contain an artificial backbone made of $\mathrm{N}$-(2-aminoethyl) glycine subunits. The nucleobases are attached to the $\alpha$-amino group by an acetic acid linker [10]. Lack of negatively charged phosphate residues provides reduced electrostatic repulsion between the PNA strand and a target RNA or DNA strand, causing exceptional thermal stability of the resulting hybrid complexes [9]. In order to improve solubility as well as intracellular delivery, a variety of modifications have been described $[11,12]$. Phosphonic ester-modified PNAs (pePNAs) represent a specific modification of the $\alpha$-carbon atom of the 
glycine and improve the solubility and binding strength of interactions [13, 14].

The evolutionary highly conserved canonical Wnt pathway has shown to be crucial in development and disease [15]. Without binding of Wnt ligand proteins to frizzled/ LRP5/6 co-receptors, $\beta$-catenin is recognised by a destruction complex including APC, Axin and GSK3 $\beta$. As a result, $\beta$-catenin is degraded. In the active state the destruction complex is not formed; $\beta$-catenin accumulates and enters the nucleus where it interacts with members of the Tcf/ Lef transcription factor family, such as Tcf3 and Lef1 [16]. During this process, Groucho/TLE proteins are replaced by $\beta$-catenin and co-activator proteins are recruited resulting in the activation of target genes $[17,18]$. Besides its major role in Wnt signalling, $\beta$-catenin is also important for cell adhesion, where it connects cadherin to the cytoskeleton through $\alpha$-catenin binding $[19,20]$.

Several components of the Wnt pathway, including APC, Axin, Tcf and $\beta$-catenin, have shown mutations relevant for human cancers [21,22]. $\beta$-catenin mutations have been found in human colorectal cancer [23] and human hepatocellular carcinoma [24]. They result in constitutively active Wnt signalling, by uncoupling $\beta$-catenin from the degradation pathway $[25,26]$. Due to its prominent role in the Wnt pathway, $\beta$-catenin has been discussed as a target for therapeutic applications [27, 28]. Targeting $\beta$-catenin showed a potential therapeutic benefit in a variety of studies, applying antisense reagents [27], peptides [29] or small molecule drugs [30].

In this study, we show a newly designed splice-based reporter assay for quantification of antisense effects, which allows a positive luminescence read out for successful splice blocking by antisense oligos. Based on this assay, a dominant negative knock-down strategy was developed for $\beta$-catenin with specific PNA and morpholino oligos. For this purpose, $\beta$-catenin was targeted in a way that the interaction with its main partners Tcf/Lef is still possible; however, interaction with essential coactivators is blocked.

\section{Materials and Methods}

\section{Plasmids}

For the splice-based reporter assay, a backbone containing a human EF1 $\alpha$ short promoter [31] driving reporter gene expression, piggybac terminal repeat sequences for genome integration [32], puromycin resistance and a luciferase internal reference was constructed. Firefly luciferase (Fluc) [33] was used as reporter gene for pSplice2basis1 together with Gaussia luciferase (Gluc) [34] as an internal reference or NanoLuc (Nluc, Promega) [35] for pSplice3basis1 combined with the internal reference Fluc. Internal references were used for normalisation in order to compensate for varying cell number and viability. The consensus SD sequence of pSplice2basis 1 and pSplice3basis1 is AGGTAAGT. $\beta$-catenin deletion constructs were generated via PCR and integrated into a pKC backbone containing a CMV promoter [36]. Mammalian two-hybrid constructs were all based on the pMC vector [37]. For details see Table $\mathrm{S} 1$.

\section{Cell Culture and Statistical Analysis}

HeLa, HEK293 T-REx (Invitrogen) as well as SW480 cells were cultured in Dulbecco's modified Eagle's medium (DMEM/GE Healthcare) including 10\% foetal bovine serum (Thermo Scientific) and 1\% penicillin/streptomycin (Thermo Scientific) in a humidified environment with $5 \% \mathrm{CO}_{2}$. Stable cell lines were generated using the piggybac transposon system [32]. Positive clones were picked after puromycin selection (Santa Cruz $1 \mu \mathrm{g} / \mathrm{mL}$ ). Quantification of gels and Western blots was performed with ImageJ. $P$ values were calculated by the Student's $t$ test. Statistical significance: ${ }^{*} p \leq 0.05 ; * * p \leq 0.01 ; * * * p \leq 0.001$.

\section{Antisense Molecules}

The synthesis of the lysine-phosphonic-ester-modified PNAs was performed as described in Jung et al. [14] by ugichem $\mathrm{GmbH}$. Phosphorodiamidate morpholino oligonucleotides (abbreviated here as morpholinos) were manufactured by Gene Tools. All antisense molecules are listed in Table S2 with PNAs showing N-terminal (4-(tri-Fluoromethyl)-phenyl)-acetyl-glycine (phenylacetate-glycine) modifications. The PNAs were dissolved in nuclease free water to $1 \mathrm{mM}$ by repeated shaking and vortexing. Finally, they were gently sonicated for $2 \mathrm{~min}$ with repeated pulses. Subsequently, the PNAs were kept at $-80{ }^{\circ} \mathrm{C}$.

\section{Transfection, Luciferase Assay and Mammalian Two-Hybrid Assay}

For transient transfection cells were seeded in a PEI-coated [38] 96-well plate at a density of $0.5 \times 10^{4}$ cells/well and grown over night (HeLa) or 48 h (HEK293 T-REx). Transfection was performed using TurboFect (Thermo Scientific) transfection reagent following instructions of the manufacturer. Measurement was performed as described [39]. For the mammalian two-hybrid experiments, $80 \mathrm{ng}$ reporter plasmid (plucF24ZF), 2 ng reference (pMcGlucS) and 2 ng bait construct (see Table S1) were co-transfected per well with 22 ng truncated $\beta$-catenin constructs (prey) into HEK293 T-REx cells. 


\section{Scraping}

Cells were seeded in a 24 -well plate with $0.3 \times 10^{5}$ cells/well and incubated overnight. $24 \mathrm{~h}$ later medium was removed and $30 \mu \mathrm{L}$ loading solution [40] including the antisense reagent (morpholino or PNA) as well as $0.1 \mathrm{mg} / \mathrm{mL}$ fluorescein-isothiocyanate-dextran (FITC-dextran FD10S, Sigma-Aldrich) was added. Subsequently, cells were scraped off the plate with a rubber policeman $5 \times$ clockwise and $5 \times$ counter clockwise, and remaining cells were washed off with $500 \mu \mathrm{L}$ DMEM including 10\% foetal bovine serum and 1\% penicillin/streptomycin (Thermo Scientific) and transferred into a fresh 24-well plate. Cells were incubated $24 \mathrm{~h}$ for recovery until RNA extraction or luciferase measurements were performed.

\section{Electroporation}

Cells were trypsinised, counted and diluted in DMEM to $3 \times 10^{7}$ cells $/ \mathrm{mL}$ and $30 \mu \mathrm{L}$ transferred to a $1 \mathrm{~mm}$ gap electroporation cuvette (VWR) pre-cooled on ice. Adjustments for electroporation (device described in [41]) on the Accupulser were: pulse width $12 \mathrm{~ms}$, pulse interval $20 \mathrm{~ms}$, train duration $250 \mathrm{~ms}$ for HeLa or $500 \mathrm{~ms}$ for SW480, voltage $60 \mathrm{~V}$ at a frequency of $1 \mathrm{kHz}$. After electroporation, cells were transferred to a fresh pre-warmed 24-well plate by flushing the cuvette with $500 \mu \mathrm{L}$ DMEM including $10 \%$ foetal bovine serum and $1 \%$ Penicillin/Streptomycin (Thermo Scientific). Another $500 \mu \mathrm{L}$ including $10 \%$ foetal bovine serum and 1\% penicillin/streptomycin (Thermo Scientific) was added, and cells were divided into two wells of a 24-well plate followed by a $48 \mathrm{~h}$ recovery under standard cell culture conditions. For determination of cytotoxicity, cells were stained with $2 \mathrm{ng} / \mu \mathrm{L}$ 7AAD (Santa Cruz) followed by analysis with a flow cytometer (CytoFLEX, Beckman Coulter).

\section{RNA Extraction and cDNA Synthesis}

For RNA extraction the GeneJET RNA Purification Kit (Thermo Scientific) was used following the instructions of the manufacturer. DNAse I (Thermo Scientific), random hexamer primers (Thermo Scientific) and RevertAid Reverse Transcriptase (Thermo Scientific) for cDNA synthesis were used according to the instructions of the manufacturer.

\section{qPCR}

Primer and probe sequences are listed in Table S2. For each reaction $25 \mu \mathrm{L}$ containing $0.2 \mu \mathrm{M}$ of each primer, $80 \mathrm{mM}$ Tris, $20 \mathrm{mM}\left(\mathrm{NH}_{4}\right)_{2} \mathrm{SO}_{4}, 0.02 \%$ Tween $20,0.2 \mu \mathrm{M}$ dNTP mix (Thermo Scientific), $0.005 \mathrm{U}$ Taq polymerase (Agrobiogen) and $1 \mu \mathrm{L}$ cDNA were used. Additionally, for qPCR
$1 \mu \mathrm{L}$ SYBR green to a final dilution of 1:10 (Sigma), $20 \mu \mathrm{g}$ bovine serum albumin and $4 \mathrm{mM} \mathrm{MgCl} 2$ or for Taqman $0.15 \mu \mathrm{M}$ Taqman probes and $3.5 \mathrm{mM} \mathrm{MgCl} 2$ were added. Measurements were taken in a Stratagene MX3000P (Agilent Technologies).

\section{Western Blot}

SW480 cells were electroporated with $32 \mu \mathrm{M}$ morpholino MO3. After 48-h recovery whole cell protein extracts were made with lysis buffer (20 mM HEPES pH 7.9, $400 \mathrm{mM}$ $\mathrm{NaCl}, 1 \mathrm{mM}$ EDTA, $0.2 \% \mathrm{NP}-40,1 \mathrm{mM}$ DTT and $0.5 \mathrm{mM}$ PMSF). $5 \mu \mathrm{g}$ of the protein extracts (determined by Bradford assay) was run on an SDS page followed by semidry blotting. Membranes were blocked $1-2 \mathrm{~h}$ in 5\% milk powder (Roth) in $1 \times$ TBS-T (10 mM Tris-Cl, pH 7.4, $150 \mathrm{mM}$ $\mathrm{NaCl}, 1$ mM EDTA, pH 8.0, 0.1\% Tween20) on a shaker. Primary antibodies were diluted 1:500 ( $\beta$-catenin sc-1496, Santa Cruz) or 1:10,000 (GAPDH sc-25778, Santa Cruz) and incubated $\mathrm{O} / \mathrm{N}$ at $4{ }^{\circ} \mathrm{C}$ shaking. Secondary antibody (HRP conjugated, goat anti-rabbit sc-2004, Santa Cruz) was added in a 1:5000 dilution with 5\% BSA in TBS-T. Signals were detected with ECL solution (Santa Cruz Biotechnology) and a ChemiDoc (Protein Simple) station, and quantification was done with ImageJ.

\section{Results}

\section{Sensitive Detection of Antisense Effects with a Splice-Based Reporter Assay}

For development of an antisense strategy targeting $\beta$-catenin, we decided to apply a splice blocking approach $[42,43]$. In order to quantify the efficiency of the antisense molecules, a splice-dependant reporter assay was established. The reporter construct was designed by positioning the AUG in the first exon and an artificial intron before the second exon containing the luciferase sequence. Splicing connects exon1 with exon 2 coding for luciferase, but in the wrong reading frame resulting in a non-functional protein (Fig. 1a). On the contrary, blocking of splicing by antisense molecules generates an mRNA including the non-spliced intron, which, however, contains an open reading frame directly combining those of exon 1 and 2, and resulting in a functional luciferase fusion protein. The design of the reporter construct further allows easy introduction of any splice donor (SD) of interest by using restriction sites flanking the SD. In order to test the assay, two stable cell lines containing a consensus SD sequence were generated (HeLa pSplice2basis1 and HeLa pSplice3basis1). Experiments applying the PNA oligo PNA1 (Fig. 1b; for information on the antisense oligos see Table S2) or the morpholino oligo MO1 (Fig. S1) showed a 


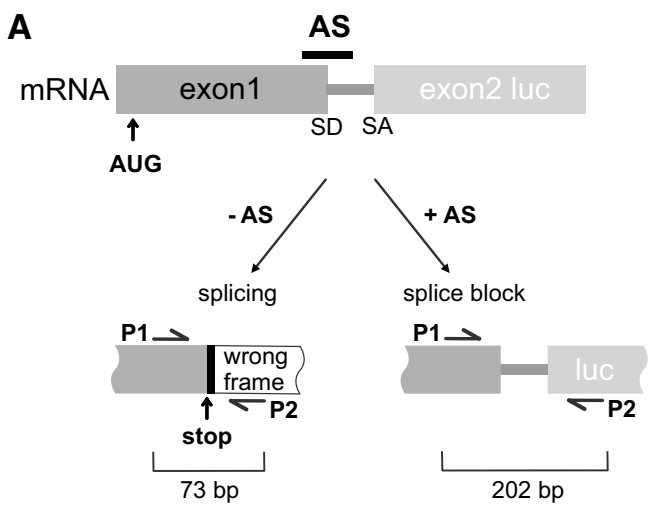

B

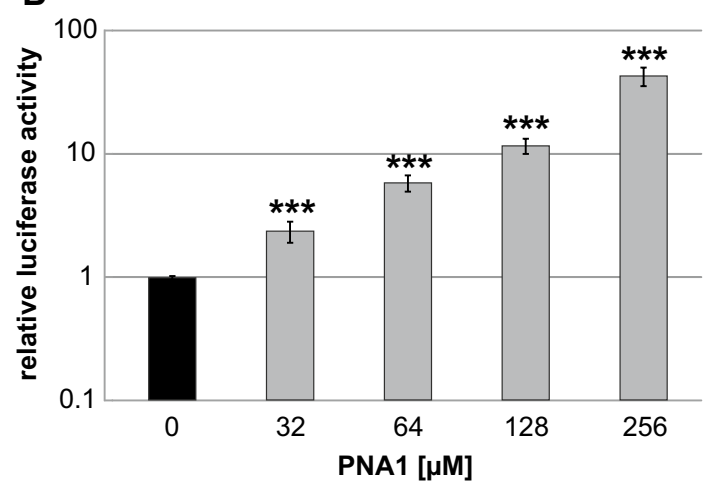

C

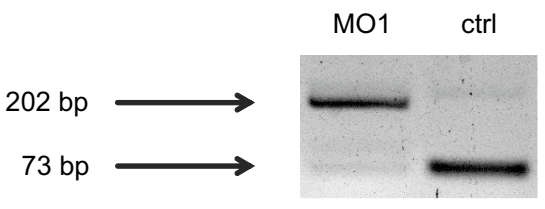

Fig. 1 Splice-based reporter assay. a Schematic view of the reporter assay. AS (antisense reagent), SD (splice donor), SA (splice acceptor), P1 and P2 (primers for PCR). b HeLa pSplice3basis1 cells were electroporated with the indicated amount of PNA1. After $24 \mathrm{~h}$ luciferase activity was determined. Nluc values were divided through internal Fluc reference and normalised to control cells (0) electroporated without PNA. Data represent mean values of at least 3 independent experiments, except for $32 \mu \mathrm{M}$ (single determination), and error bars indicate SEM. c PCR from cDNA of antisense-treated pSplice3basis1 cells treated with $16 \mu \mathrm{M}$ MO1 compared to equally treated control cells without reagent (ctrl). Scraping was used for delivery, and cells were harvested after $24 \mathrm{~h}$

clear increase in luciferase activity (up to 49- and 13-fold, respectively). A luciferase-based internal reference was used to correct for cell number and to detect toxic effects of the antisense molecules. A concentration-dependent steady increase in luciferase activity was observed and even at the highest amounts of PNAs no drop in activity was observed, indicating no toxicity at the applied concentration range. The low cytotoxicity of the PNAs could be confirmed by flow cytometry. A concentration of $256 \mu$ M PNA1 showed no effect on the cell number (Fig. S2A) or the amount of dead cells (7AAD positive; Fig. S2B), compared to control cells electroporated without PNA. However, at $512 \mu \mathrm{M}$ the total cell number slightly decreased and the number of dead cells increased. To confirm a splice blocking effect cDNA of HeLa pSplice3basis 1 cells was analysed with PCR. The expected switch in splicing could be demonstrated using primers ( $\mathrm{P} 1$ and $\mathrm{P} 2$ ) flanking the intron. A 73 bp product was observed for normal splicing, whereas addition of a splice blocking antisense oligo resulted in a 202 bp PCR fragment including the intron (Fig. 1a, c). The splice blocking efficiency of the morpholino oligo was strong, as indicated by the quantification of the PCR fragments resulting in a 590fold change of the ratio upon treatment (Fig. 1c).

\section{Splice Blocking Strategy for $\beta$-Catenin}

In order to develop a strategy for targeting of $\beta$-catenin, we first tested multiple PNAs directed against the SD regions of various exons and selected the exon $13 \mathrm{SD}$ for further experiments (Fig. 2a). Similar to the assay presented in Fig. 1, we established a reporter construct containing this SD and generated a stable reporter cell line (HeLa pSplice3 $\beta$ cat Ex 13 SD). Using this assay for splice blocking, we tested 4 PNAs targeting the exon $13 \mathrm{SD}$, all with a length of 16 nucleotides and differing by a 2 nucleotide shift on their target sequences (Table S3). We observed increased luciferase levels for all 4 PNAs, and strongest luciferase induction was observed for PNA18 (Fig. 2b; 6.4-fold induction).

In order to demonstrate that targeting of exon $13 \mathrm{SD}$ reduced the amount of properly spliced $\beta$-catenin mRNA, a qPCR assay in SW480 cells was performed. $24 \mathrm{~h}$ after electroporation with the antisense molecules, $\beta$-catenin mRNA levels were detected with primers in exons 13 and 14, respectively (Table S3). PNA18 showed significant effects also in this assay (reduction to $79 \% ; p=0.0011$ ). Contrary to the luciferase-based assay, PNAs 4, 15 and 19 did not generate a significant reduction in the qPCR assay, whereas a morpholino oligo (MO3) directed to this SD resulted in a reduction of correctly spliced $\beta$-catenin mRNA to $59 \%$ compared to the mock-treated reference (Table S3). To demonstrate that the reduced detection of $\beta$-catenin mRNA was caused by aberrant splicing, an RT-PCR experiment was performed in SW480 cells (Fig. 3a). The appearance of a $304 \mathrm{bp}$ PCR product indicates the presence of intron 13 in the mRNA, whereas a 50-bp fragment appears for correctly processed mRNA, lacking the intron. Electroporation of both PNA18 and MO3 resulted in the appearance of a 304-bp fragment indicating a splice block at exon 13 SD (Fig. 3a). Furthermore, the antisense effect on $\beta$-catenin could be verified on the protein level. A Western blot with extracts harvested from SW480 cells showed a reduction of $\beta$-catenin protein to $45 \%$ compared to non-treated controls (Fig. 3b).

In order to see whether the $\beta$-catenin knock-down had an effect on established Wnt target genes, we quantified 


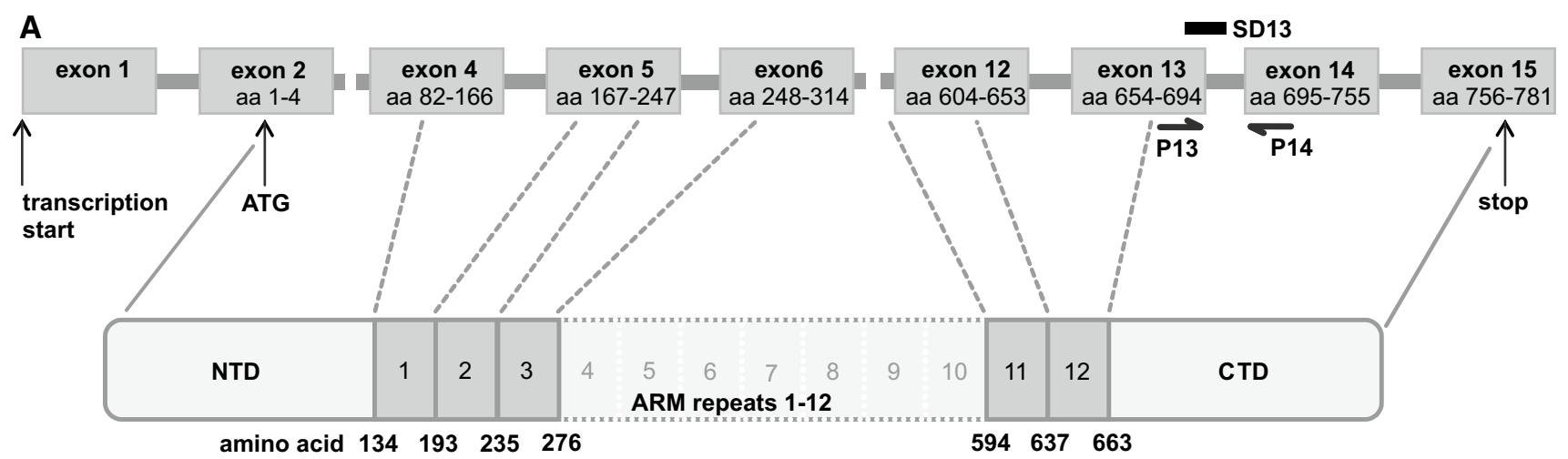

B

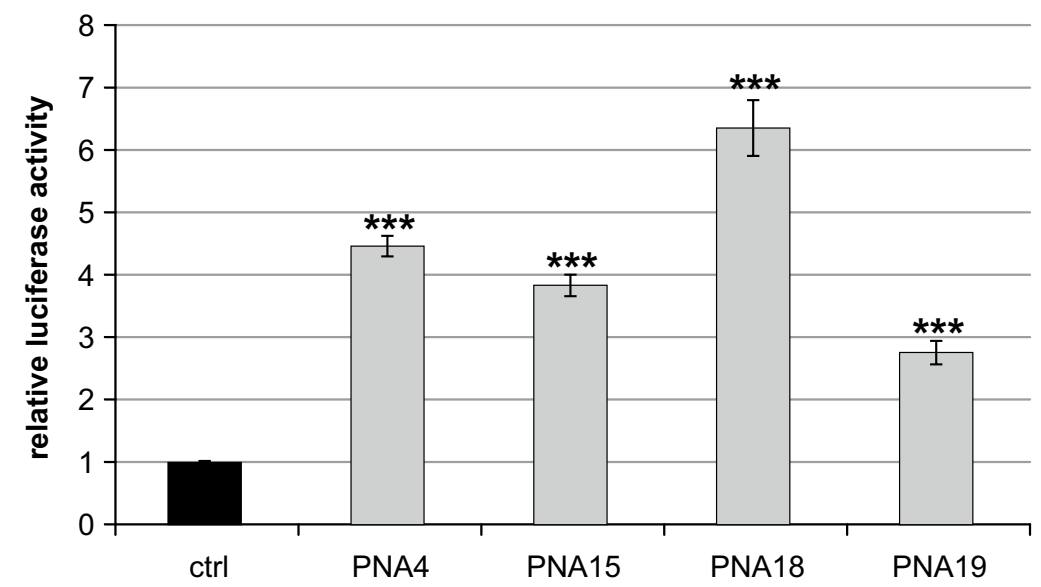

Fig. 2 Targeting $\beta$-catenin with PNA and morpholino oligos. a Schematic view of the $\beta$-catenin gene including exon/intron map with positions of exon $13 \mathrm{SD}$ (SD13) and splice-specific PCR primers (P13, P14), numbering of exons according to NM001904.3. The positions of the exons relative to the armadillo repeats of the protein are indicated. Abbreviations: amino acid (aa), armadillo (ARM), N-terminal domain (NTD), C-terminal domain (CTD). b Luciferase assay with different PNAs targeting $\beta$-catenin at the SD of exon 13. HeLa pSplice $3 \beta$ cat Ex13 SD cells were electroporated with $128 \mu \mathrm{M}$ of the indicated PNAs. Nluc values were divided through the internal reference Fluc and normalised to control cells (ctrl) electroporated without PNA. Data represent mean values of at least 3 independent experiments, and error bars indicate SEM

of activity due to loss of interaction with the transcriptional co-activator $\mathrm{CBP} / \mathrm{p} 300$, which depends on an intact C-terminal domain of $\beta$-catenin (Fig. 4a) [44]. To verify the reduced transactivation, we expressed a $\beta$-catenin variant truncated after exon 13 in Hela cells and measured its activity in a luciferase reporter assay (Fig. S3). Whereas full-length $\beta$-catenin activated the reporter 5.8-fold, the truncated protein resulted in luciferase values close to the basal level (1.4-fold reporter activation compared to the empty expression vector). However, $\beta$-catenin not only serves functions in transcriptional regulation, but also plays a critical role in cell adhesion. Ideally, targeting of B-catenin should block its transcriptional activity, but retain its cell adhesion function. This function depends on protein-protein interactions with cadherin and $\alpha$-catenin. Whereas the $\alpha$-catenin interaction has been mapped to the $\mathrm{N}$-terminal domain and armadillo repeat 1 [45], cadherin interacts with the complete central region of $\beta$-catenin $\beta$-catenin protein. The truncation would explain a lack 
A

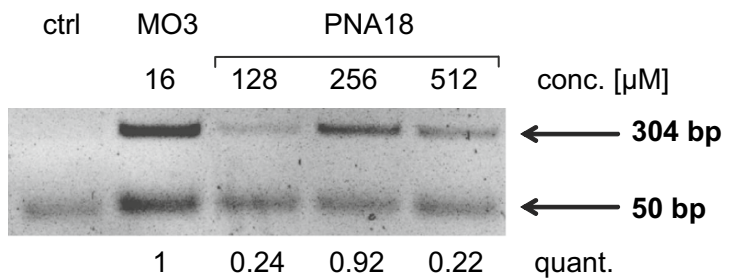

B
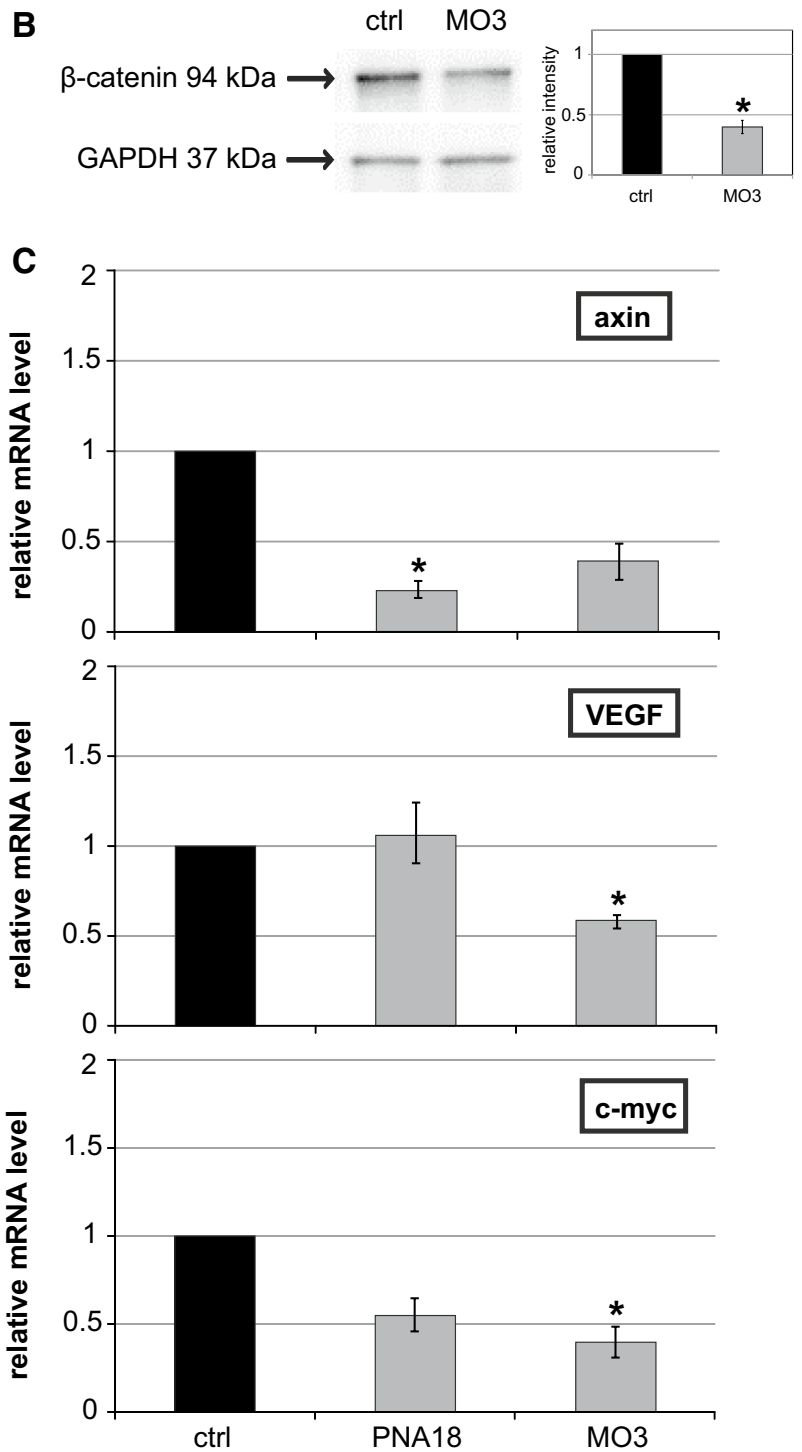

Fig. 3 Effect of splice block at exon 13 of $\beta$-catenin in SW480 cells. a SW480 cells were electroporated with the indicated amounts of MO3 and PNA18. PCR from cDNA with primers P13 and P14, specific for the presence of intron 13 (304 bp band) as a result of the splice block and 50 bp resulting from normal splicing. Quantification of the band ratio normalised to MO3 is shown below (quant.). b Effect on $\beta$-catenin protein level in SW480 cells electroporated with $32 \mu \mathrm{M} \mathrm{MO}$, extracts prepared after $48 \mathrm{~h}$. Bands for $\beta$-catenin and GAPDH are indicated. Quantification is shown for two independent experiments (resulting in a mean protein level of $40 \%$ for the MO3-treated samples compared to the control). c mRNA levels of the $\beta$-catenin target genes axin, VEGF and c-myc determined by qPCR normalised to GAPDH and mock-treated control cells (ctrl). SW480 cells were electroporated with MO3 $(16 \mu \mathrm{M})$ and PNA18 $(256 \mu \mathrm{M})$. Data represent mean values of duplicates. Error bars indicate SEM
(Fig. 4a) [46]. The function of $\beta$-catenin in cell adhesion could therefore be affected by truncations of the protein upon a splice block.

In order to investigate the effects of the $\beta$-catenin truncations on its interactions, we performed a mammalian two-hybrid analysis [39]. We selected blocking of two SD regions for the analysis; in addition to the SD of exon 13 (aa 654-694) we used that of exon 6 (aa 248-314) as a control, which leads to truncations lacking the majority of the armadillo repeats. In both cases we considered the presence of a non-spliced intron or skipping of the upstream exon due to the splice block. In addition, the presence of prominent cryptic splice sites in the vicinity of the SD was excluded [47]. We then generated expression constructs by PCR according to the expected splice products. For exon 6 we generated $\beta$-catenin(+I6) (intron 6 added) and $\beta$-catenin(E6skip) (exon 6 skipped) and for exon $13 \beta$-catenin $(+\mathrm{I} 13)$ (intron 13 added) and $\beta$-catenin(E13skip) (exon 13 skipped); the constructs were extended until the first in frame stop codon. The four truncated $\beta$-catenin versions served as prey in the mammalian two-hybrid assay and were $\mathrm{N}$-terminally fused to the p65 transactivation domain. Tcf3, Lef1, cadherin and $\alpha$-catenin were used as baits, fused to the DNA binding domain ZFHD [39].

For all baits interactions with full-length $\beta$-catenin as prey were clearly detectable (Fig. 4b). Also an interaction of $\alpha$-catenin was detectable for all baits; however, the interactions of Tcf3 and Lef1 were clearly reduced for $\beta$-catenin(+I6) and $\beta$-catenin(E6skip), compared to that of $\beta$-catenin(+I13), $\beta$-catenin(E13skip) and $\beta$-catenin full length. Finally, the cadherin interaction was also strongly reduced for the exon 6 truncations (+I6 and E6skip), but the exon 13 truncations (+I13 and E13skip) both showed luciferase activities similar to full-length $\beta$-catenin. Therefore, truncations of $\beta$-catenin due to splice blocking at exon 13 SD retain the interactions necessary for a function in cell adhesion.

\section{Dominant Negative Effect of $\beta$-Catenin Truncations}

Loss of the C-terminus is expected to result in a lack of transcriptional activity, but the mammalian two-hybrid experiments revealed binding of Tcf/Lef to the exon 13 truncations of $\beta$-catenin. This combination could be the basis for a dominant negative effect, where truncated $\beta$-catenin proteins would interfere with binding of wildtype proteins to Tcf/Lef. To test this, we transfected a $\beta$-catenin full-length expression construct together with different amounts of those for the truncated $\beta$-catenin versions. A co-transfected luciferase reporter construct containing six Tcf/Lef binding sites [49] was used for detection of Wnt pathway activity. Compared to the empty expression vector, all truncated versions resulted 
A

$\beta$ (E6skip)

$\beta(+16)$

$\beta$ (E13skip)

$\beta(+113)$
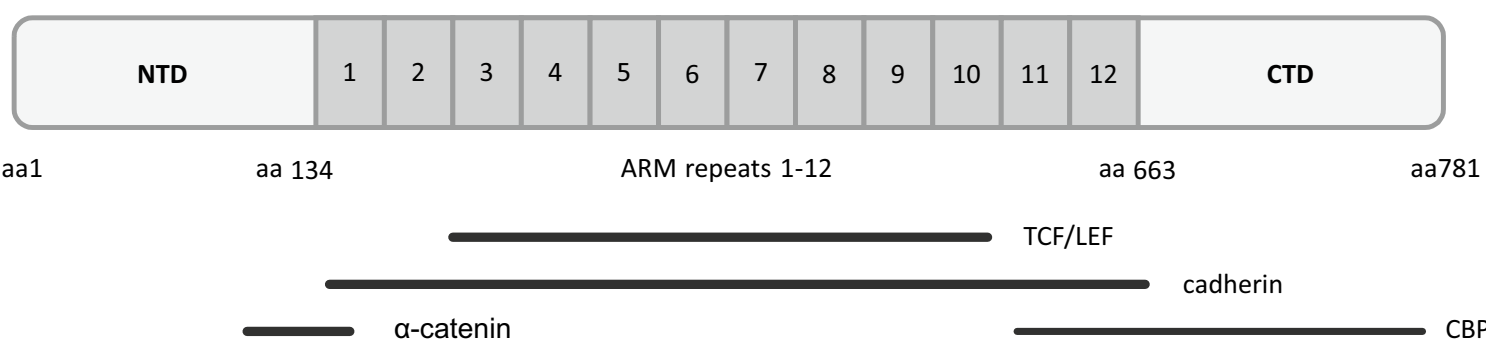

$\mathrm{CBP} / \mathrm{p} 300$

B
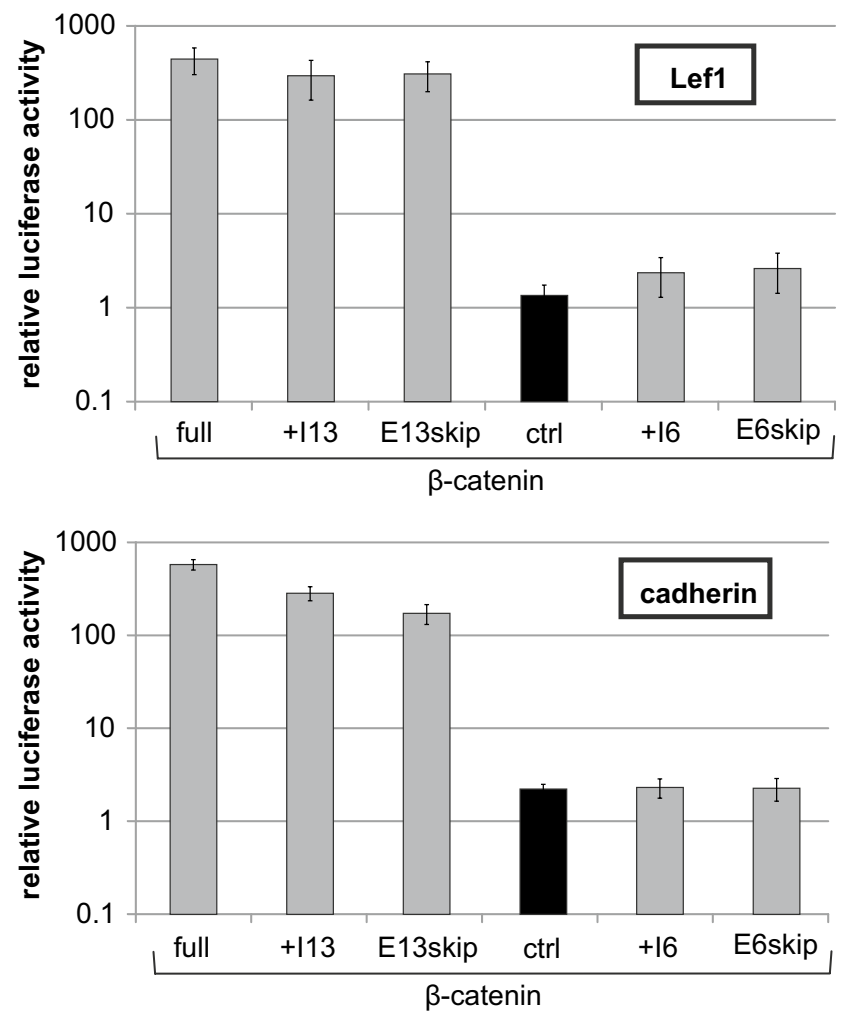

Fig. 4 Protein-protein interactions of truncated $\beta$-catenin. a Schematic presentation of truncated $\beta$-catenin versions. Position of armadillo (ARM) repeats is indicated as well as the interaction sites of known binding partners [45, 46, 48]. aa (amino acids), NTD (N-terminal domain), CTD (C-terminal domain), ARM (armadillo). b Mammalian two-hybrid assay with the baits Lef1 (pMCLef1mZFb6), Tcf3 (pMCZFb6Tcf3), cadherin (pMCZFghe-cadherin) or $\beta$-catenin (pMCZFg alpha-catenin) together with the preys $\beta$-catenin full length

in reduced activity of $\beta$-catenin. However, strongest effects were seen for the two exon 13 constructs $(\beta$-catenin $(+\mathrm{I} 13)$, reduction to $31 \%$ and $\beta$-catenin(E13skip), reduction to $23 \%$ (Fig. 5a). The most effective truncation of $\beta$-catenin(E13skip) showed effects already at low
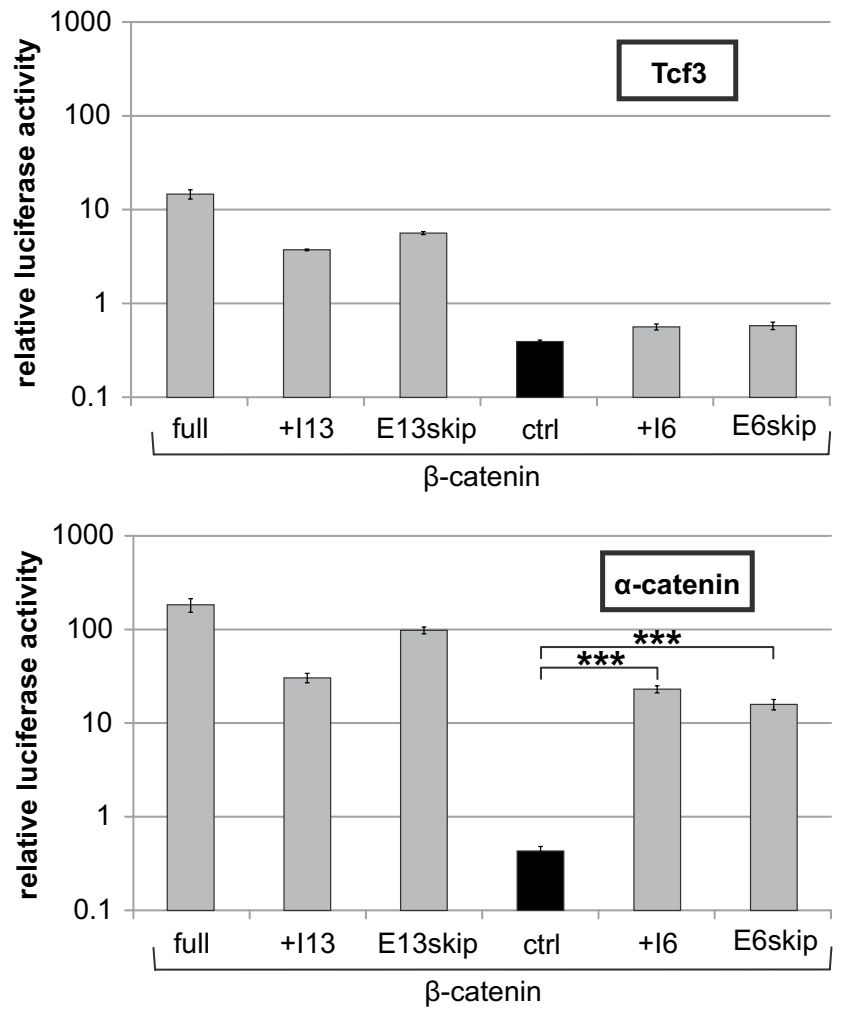

(full; pMC65gDP $\beta$ cat), $\beta$-catenin(+I13) (pMC65gDP $\beta$ cat[1-694]), $\beta$-catenin(E13skip) $\quad(\mathrm{pMC} 65 \mathrm{gDP} \beta \mathrm{cat}[1-653]), \quad \beta$-catenin $(+\mathrm{I} 6)$ (pMC65gDP $\beta$ cat[plusintron6]), $\quad \beta$-catenin(E6skip) (pMC65gDP $\beta$ cat[exon6skip]) and no prey (ctrl). All Fluc values were divided through the internal reference Gluc and then normalised to samples lacking bait and prey. Data represent mean values of at least 3 independent experiments, and error bars indicate SEM

concentrations ( $3 \mathrm{ng}$; Fig. 5b), whereas co-transfection of full-length $\beta$-catenin had the opposite effect leading to an increase in the luciferase activity of the Wnt responsive reporter. In this experiment the activity of the fulllength protein can be directly compared with the dominant 

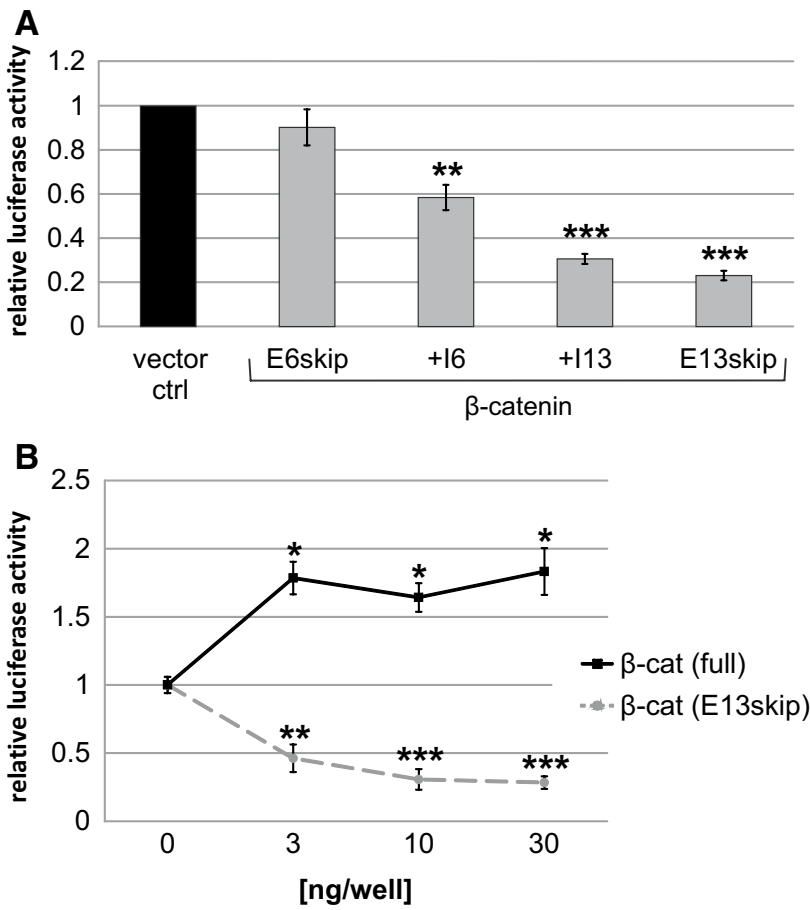

Fig. 5 Dominant negative effect of truncated $\beta$-catenin versions. a $70 \mathrm{ng}$ pMlucF6lefcons, $2 \mathrm{ng}$ pMCGlucS and $10 \mathrm{ng} \beta$-catenin full length [pKCDP $\beta$ cat] were co-transfected into HeLa cells with $30 \mathrm{ng}$ truncated $\beta$-catenin versions: $\mathrm{pKCDP} \beta \mathrm{cat}(\mathrm{E} 6 \mathrm{skip}), \mathrm{pKCDP} \beta \mathrm{cat}(+\mathrm{I} 6)$, pKCDP $\beta$ cat (1-694)(+I13), pKCDP $\beta$ cat(1-653)(E13skip) and empty pKC vector (vector ctrl). Measurements were taken $24 \mathrm{~h}$ after transfection. All values were normalised to samples with empty expression vector pKC. Data represent mean values of at least 3 independent experiments, and error bars indicate SEM. b Concentration-dependent dominant negative effect of $\beta$-catenin(E13skip) (pKCDP $\beta$ cat [1-653]) compared to $\beta$-catenin full length (full; pKCDP $\beta$ cat). $70 \mathrm{ng}$ pMlucF6lefcons, $2 \mathrm{ng}$ pMCGlucS and $10 \mathrm{ng}$ pKCDP $\beta$ cat were co-transfected with 3,10 and $30 \mathrm{ng}$ pKCDP $\beta$ cat or pKCDP $\beta$ cat (1-653) into HeLa cells. Values were normalised to controls without expression vector for $\beta$-catenin. All Fluc reporter values were divided through Gluc internal reference. Data represent mean values of at least 3 independent experiments, and error bars indicate SEM

negative effect of the truncated version, thus confirming the strict dependence of $\beta$-catenin on an intact $\mathrm{C}$-terminus for canonical Wnt signalling.

\section{Discussion}

\section{Splice-Based Reporter Assay}

Alternative splicing is widely used by nature to extend the repertoire of the proteome, and aberrant splicing has been shown to be the cause for a variety of diseases [50]. Antisense molecules bind to mRNA and thus have the potential to manipulate the access of the splice machinery. Whereas most applications aim to inactivate gene function by generating non-functional proteins, also correction of aberrant splicing has been tested as a therapeutic strategy for diseases like $\beta$-Thalassaemia [43, 51], also applying reporter assays [52]. We established a luciferase-based assay which shows several advantages. The splice target sequence is integrated into an otherwise completely artificial surrounding and can easily be exchanged. The specific design of the intron allows a positive readout for the assay, meaning that successful splice blocking results in a luciferase signal above the background (Fig. 1a).

Using this reporter we developed stable cell lines for two different splice sites and in both cases observed sensitive and reliable signals for splice blocking oligos. In the case of $\beta$-catenin 4 different PNAs directed against the exon $13 \mathrm{SD}$ resulted in positive signals in the luciferase assay (Fig. 2b; $p \leq 0.02$ for all 4 PNAs). On the other hand, a qPCR-based assay showed a significant reduction of $\beta$-catenin mRNA only for PNA18 (Table $\mathrm{S} 3 ; p=0.001$ ), whereas non-significant values were obtained for the other 3 PNAs $(p \geq 0.3)$. Main reason for this discrepancy is the error rates, which are considerably smaller for the luciferase assay (compare Fig. $2 b$ and Table S3). Therefore, the optimisation of conditions for splice blocking works highly efficient with the presented reporter assay. Furthermore, compared to alternatives as qPCR or Western blot this assay is fast and simple.

PNAs show a number of advantageous properties compared to other antisense reagents. Due to the neutral charge of their backbone and the lack of electrostatic repulsion, they bind RNA with high affinity. Consequently, short antisense molecules (13-18 bases) are sufficient for selective binding. The small size makes them ideal for therapeutic applications, and the intracellular delivery can be further boosted using cell penetrating peptides [53], nanoparticles [54], liposomes [55] or modifications of the PNA backbone [56]. Phosphonic ester modifications of the backbone improve both the cellular uptake [57] and the knock-down efficiency [13, 14]. The phosphonic ester PNAs used in this study induced splice blocking (Fig. 1c), comparable to previous studies with PNAs [58, 59].

\section{Targeting $\beta$-Catenin with Splice-Based Antisense Molecules}

Due to its relevance in cancer development, $\beta$-catenin has become a favoured target for nouveau cancer therapy strategies. Recent publications show decreased tumour burden within varying cancer types after targeting $\beta$-catenin with different approaches. PNAs have already been used for $\beta$-catenin knock-down in liver tumour cells [56] or antisense oligodeoxynucleotides for $\beta$-catenin targeting in xenograft mice with SW480 colon carcinoma cells [60]. Furthermore, small molecule inhibitors [61] or siRNA [62] were successfully used within xenograft mouse models. Nonetheless, 
rigorous targeting of $\beta$-catenin may be problematic due to the essential role of $\beta$-catenin in non-cancer related functions as cell-cell adhesion [63].

Antisense-mediated splice blocking as a strategy to reduce $\beta$-catenin levels in the cell worked in our approach and resulted in reduced levels of $\beta$-catenin mRNA, protein and consequently also of target genes (Fig. 3). A specific advantage of our splice-based antisense strategy is the generation of a dominant negative protein version. Targeting of exon $13 \mathrm{SD}$ results in a C-terminally truncated protein, which lacks transactivation properties, but retains its interaction with Tcf/Lef proteins, thus competing with wild-type $\beta$-catenin (Figs. 4, 5). Most importantly, the truncation does not interfere with interactions of $\beta$-catenin with $\alpha$-catenin and cadherin (Fig. 4), both critical for its function in cell adhesion. Therefore, our splice blocking antisense approach generates a truncated protein with the potential to efficiently interfere with Wnt signalling in a dominant negative manner, but at the same time retaining critical functions of $\beta$-catenin in cell adhesion. A next step would be to test this approach in an in vivo model.

\section{Conclusion}

Herein, we present a splice-based reporter assay for accurate quantification of knock-down effects of antisense molecules. Furthermore, a strategy for targeting $\beta$-catenin next to its C-terminal transactivation domain resulted in a dominant negative protein, which efficiently blocks Wnt signalling, but retains interactions with cell adhesion molecules.

Acknowledgements Open access funding provided by FH Campus Wien - University of Applied Sciences. The work was supported by the Austrian Research Promotion Agency (FFG, Grant 836444) and the City of Vienna (MA23-project 18-18).

Authors' Contributions MV and ER were responsible for experimental design, analysis, execution and writing of the manuscript. $\mathrm{CH}$ built and maintained the electroporator. MA, HB, BW and TL performed the PNA design and synthesis. TC was responsible for experimental design, analysis, writing, communication and supervising of the project. All authors read and approved the final manuscript.

\section{Compliance with Ethical Standards}

Conflict of interest MA, HB, BW and TL were full employees of the company ugichem $\mathrm{GmbH}$ that developed PNAs for therapeutic applications. Design and synthesis of the PNAs were performed at the ugichem $\mathrm{GmbH}$, which became insolvent 2015.

Open Access This article is distributed under the terms of the Creative Commons Attribution 4.0 International License (http://creativeco mmons.org/licenses/by/4.0/), which permits unrestricted use, distribution, and reproduction in any medium, provided you give appropriate credit to the original author(s) and the source, provide a link to the Creative Commons license, and indicate if changes were made.

\section{References}

1. Zamecnik, P. C., \& Stephenson, M. L. (1978). Inhibition of Rous sarcoma virus replication and cell transformation by a specific oligodeoxynucleotide. Proceedings of the National Academy of Sciences, 75(1), 280-284.

2. Mansoor, M., \& Melendez, A. J. (2008). Advances in antisense oligonucleotide development for target identification, validation, and as novel therapeutics. Gene Regulation and Systems Biology, 2, 275-295.

3. Perry, C. M., \& Barman Balfour, J. A. (1999). Fomivirsen. Drugs, 57(3), 375-380.

4. Vinores, S. A. (2006). Pegaptanib in the treatment of wet, agerelated macular degeneration. International Journal of Nanomedicine, 1(3), 263-268.

5. Moreno, P., \& Pego, A. P. (2014). Therapeutic antisense oligonucleotides against cancer: Hurdling to the clinic. Frontiers in Chemistry, 2(October), 87.

6. Warren, T. K., Shurtleff, A. C., \& Bavari, S. (2012). Advanced morpholino oligomers: A novel approach to antiviral therapy. Antiviral Research, 94(1), 80-88.

7. Summerton, J. (2007). Morpholino, siRNA, and S-DNA compared: Impact of structure and mechanism of action on off-target effects and sequence specificity. Current Topics in Medicinal Chemistry, 7(7), 651-660.

8. Blum, M., De Robertis, E. M., Wallingford, J. B., \& Niehrs, C. (2015). Morpholinos: Antisense and sensibility. Developmental Cell, 35(2), 145-149.

9. Egholm, M., Buchardt, O., Christensen, L., Behrens, C., Freier, S. M., Driver, D. A., et al. (1993). PNA hybridizes to complementary oligonucleotides obeying the Watson-Crick hydrogen-bonding rules. Nature, 365(6446), 566-568.

10. Nielsen, P. G., Egholm, M., Berg, R. H., \& Buchardt, O. (1991). Sequence-selective recognition of DNA by strand displacement with a thymine-substituted polyamide. Science, 254(5037), $1497-1500$.

11. Kumar, P., \& Jain, D. R. (2015). C $\gamma$-Aminopropylene peptide nucleic acid (amp-PNA): Chiral cationic PNAs with superior PNA: DNA/RNA duplex stability and cellular uptake. Tetrahedron, 71(21), 3378-3384.

12. Bohländer, P. R., Vilaivan, T., \& Wagenknecht, H.-A. (2015). Strand displacement and duplex invasion into double-stranded DNA by pyrrolidinyl peptide nucleic acids. Organic \& Biomolecular Chemistry, 13(35), 9223-9230.

13. Dorn, S., Aghaallaei, N., Jung, G., Bajoghli, B., Werner, B., Bock, H., et al. (2012). Side chain modified peptide nucleic acids (PNA) for knock-down of six 3 in medaka embryos. BMC Biotechnology, 12(1), 50.

14. Jung, G., Dorn, S., Aghaallaei, N., Bajoghli, B., Riegel, E., Bock, H., et al. (2018). The function of Tcf3 in medaka embryos: Efficient knock down with pePNAs. BMC Biotechnology, $18,1$.

15. Nusse, R., \& Varmus, H. E. (1992). Wnt genes. Cell, 69(7), 1073-1087.

16. Mao, C. D., \& Byers, S. W. (2011). Cell-context dependent TCF/ LEF expression and function: Alternative tales of repression, de-repression and activation potentials. Critical Reviews ${ }^{\mathrm{TM}}$ in Eukaryotic Gene Expression, 21(3), 207-236.

17. Henderson, W. R., Chi, E. Y., Ye, X., Nguyen, C., Tien, Y. T., Zhou, B., et al. (2010). Inhibition of Wnt/-catenin/CREB binding 
protein (CBP) signaling reverses pulmonary fibrosis. Proceedings of the National Academy of Sciences, 107(32), 14309-14314.

18. Clevers, H. (2006). Wnt/ $\beta$-catenin signaling in development and disease. Cell, 127(3), 469-480.

19. Nelson, W. J. (2004). Convergence of Wnt, $\beta$-catenin, and cadherin pathways. Science, 303(5663), 1483-1487.

20. Valenta, T., Hausmann, G., \& Basler, K. (2012). The many faces and functions of $\beta$-catenin. The EMBO Journal, 31(12), 2714-2736.

21. Polakis, P. (2007). The many ways of Wnt in cancer. Current Opinion in Genetics \& Development, 17(1), 45-51.

22. Rubinfeld, B. (1997). Stabilization of beta-catenin by genetic defects in melanoma cell lines. Science, 275(5307), 1790-1792.

23. Ilyas, M., Tomlinson, I. P. M., Rowan, A., Pignatelli, M., \& Bodmer, W. F. (1997). $\beta$-catenin mutations in cell lines established from human colorectal cancers. Proceedings of the National Academy of Sciences, 94(19), 10330-10334.

24. Okabe, H., Kinoshita, H., Imai, K., Nakagawa, S., Higashi, T., Arima, K., et al. (2016). Diverse basis of $\beta$-catenin activation in human hepatocellular carcinoma: Implications in biology and prognosis. PLoS One, 11(4), e0152695.

25. Tien, L. T., Ito, M., Nakao, M., Niino, D., Serik, M., Nakashima, M., et al. (2005). Expression of beta-catenin in hepatocellular carcinoma. World Journal of Gastroenterology, 11(16), 2398-2401.

26. Bienz, M., \& Clevers, H. (2000). Linking colorectal cancer to Wnt signaling. Cell, 103(2), 311-320.

27. Roh, H., Green, D. W., Boswell, C. B., Cells, C., Pippin, J. A., \& Drebin, J. A. (2001). Suppression of $\beta$-catenin inhibits the neoplastic growth of APC-mutant colon cancer cells suppression of B-catenin inhibits the neoplastic growth of APC-mutant colon. Cancer Research, 61(17), 6563-6568.

28. Luu, H. H., Zhang, R., Haydon, R. C., Rayburn, E., Kang, Q., Si, W., et al. (2004). Wnt/ $\beta$-catenin signaling pathway as novel cancer drug targets. Current Cancer Drug Targets, 4(8), 653-671.

29. Grossmann, T. N., Yeh, J. T.-H., Bowman, B. R., Chu, Q., Moellering, R. E., \& Verdine, G. L. (2012). Inhibition of oncogenic Wnt signaling through direct targeting of $\beta$-catenin. Proceedings of the National Academy of Sciences, 109(44), 17942-17947.

30. Hahne, G., \& Grossmann, T. N. (2013). Direct targeting of $\beta$-catenin: Inhibition of protein-protein interactions for the inactivation of Wnt signaling. Bioorganic \& Medicinal Chemistry, 2l(14), 4020-4026.

31. Wan Kim, D., Uetsuki, T., Kaziro, Y., Yamaguchi, N., \& Sugano, S. (1990). Use of the human elongation factor $1 \alpha$ promoter as a versatile and efficient expression system. Gene, 91(2), 217-223.

32. Wang, H., Fraser, M. J., \& Cary, L. C. (1989). Transposon mutagenesis of baculoviruses: Analysis of TFP 3 lepidopteran transposon insertions at the FP locus of nuclear polyhedrosis viruses. Gene, 81(1), 97-108.

33. de Wet, J. R., Wood, K. V., DeLuca, M., Helinski, D. R., \& Subramani, S. (1987). Firefly luciferase gene: Structure and expression in mammalian cells. Molecular and Cellular Biology, 7(2), 725-737.

34. Verhaegen, M., \& Christopoulos, T. K. (2002). Recombinant gaussia luciferase. overexpression, purification, and analytical application of a bioluminescent reporter for DNA hybridization. Analytical Chemistry, 74(17), 4378-4385.

35. Hall, M. P., Unch, J., Binkowski, B. F., Valley, M. P., Butler, B. L., Wood, M. G., et al. (2012). Engineered luciferase reporter from a deep sea shrimp utilizing a novel imidazopyrazinone substrate. ACS Chemical Biology, 7(11), 1848-1857.

36. Heimbucher, T., Murko, C., Bajoghli, B., Aghaallaei, N., Huber, A., Stebegg, R., et al. (2007). Gbx2 and Otx2 interact with the WD40 domain of groucho/Tle corepressors. Molecular and Cellular Biology, 27(1), 340-351.
37. Fink, M., Flekna, G., Ludwig, A., Heimbucher, T., \& Czerny, T. (2006). Improved translation efficiency of injected mRNA during early embryonic development. Developmental Dynamics, 235(12), 3370-3378.

38. Vancha, A. R., Govindaraju, S., Parsa, K. V., Jasti, M., GonzálezGarcía, M., \& Ballestero, R. P. (2004). Use of polyethyleneimine polymer in cell culture as attachment factor and lipofection enhancer. BMC Biotechnology, 4(1), 23.

39. Riegel, E., Heimbucher, T., Höfer, T., \& Czerny, T. (2017). A sensitive, semi-quantitative mammalian two-hybrid assay. BioTechniques, 62, 206-214.

40. Fechheimer, M., Boylan, J. F., Parker, S., Sisken, J. E., Patel, G. L., \& Zimmer, S. G. (1987). Transfection of mammalian cells with plasmid DNA by scrape loading and sonication loading. Proceedings of the National Academy of Sciences, 84(23), 8463-8467.

41. Jung, G., Hug, M., Halter, C., Friesenhengst, A., Walzer, J., \& Czerny, T. (2013). Diffusion of small molecules into medaka embryos improved by electroporation. BMC Biotechnology, 13(1), 53.

42. Veltrop, M., \& Aartsma-Rus, A. (2014). Antisense-mediated exon skipping: Taking advantage of a trick from Mother Nature to treat rare genetic diseases. Experimental Cell Research, 325(1), 50-55.

43. Kole, R., Krainer, A. R., \& Altman, S. (2012). RNA therapeutics: Beyond RNA interference and antisense oligonucleotides. Nature Reviews Drug Discovery, 11(2), 125.

44. Vleminckx, K., Kemler, R., \& Hecht, A. (1999). The C-terminal transactivation domain of beta-catenin is necessary and sufficient for signaling by the LEF-1/beta-catenin complex in Xenopus laevis. Mechanisms of Development, 81(1-2), 65-74.

45. Pokutta, S., \& Weis, W. (2000). Structure of the dimerization and beta-catenin-binding region of alpha-catenin. Molecular Cell, 5(3), 533-543.

46. Orsulic, S., Huber, O., Aberle, H., Arnold, S., \& Kemler, R. (1999). E-cadherin binding prevents beta-catenin nuclear localization and beta-catenin/LEF-1-mediated transactivation. Journal of cell science, 112(Pt 8), 1237-1245.

47. Hebsgaard, S. M., Korning, P. G., Tolstrup, N., Engelbrecht, J., Rouzé, P., \& Brunak, S. (1996). Splice site prediction in Arabidopsis thaliana pre-mRNA by combining local and global sequence information. Nucleic Acids Research, 24(17), 3439-3452.

48. Xing, Y., Takemaru, K.-I., Liu, J., Berndt, J. D., Zheng, J. J., Moon, R. T., et al. (2008). Crystal Structure of a Full-Length $\beta$-Catenin. Structure, 16(3), 478-487.

49. Hsu, S. C., Galceran, J., \& Grosschedl, R. (1998). Modulation of transcriptional regulation by LEF-1 in response to Wnt- 1 signaling and association with beta-catenin. Molecular and Cellular Biology, 18(8), 4807-4818.

50. Scotti, M. M., \& Swanson, M. S. (2015). RNA mis-splicing in disease. Nature Reviews Genetics, 17(1), 19-32.

51. Sierakowska, H., Sambade, M. J., Agrawal, S., \& Kole, R. (1996). Repair of thalassemic human-globin mRNA in mammalian cells by antisense oligonucleotides. Proceedings of the National Academy of Sciences, 93(23), 12840-12844.

52. Bahal, R., Ali McNeer, N., Quijano, E., Liu, Y., Sulkowski, P., Turchick, A., et al. (2016). In vivo correction of anaemia in $\beta$-thalassemic mice by $\gamma$ PNA-mediated gene editing with nanoparticle delivery. Nature Communications, 7, 13304.

53. Ivanova, G. D., Arzumanov, A., Abes, R., Yin, H., Wood, M. J. A., Lebleu, B., et al. (2008). Improved cell-penetrating peptidePNA conjugates for splicing redirection in HeLa cells and exon skipping in mdx mouse muscle. Nucleic Acids Research, 36(20), 6418-6428.

54. Beavers, K. R., Werfel, T. A., Shen, T., Kavanaugh, T. E., Kilchrist, K. V., Mares, J. W., et al. (2016). Porous silicon and polymer nanocomposites for delivery of peptide nucleic acids as antiMicroRNA therapies. Advanced Materials, 28(36), 7984-7992. 
55. Avitabile, C., Accardo, A., Ringhieri, P., Morelli, G., Saviano, M., Montagner, G., et al. (2015). Incorporation of naked peptide nucleic acids into liposomes leads to fast and efficient delivery. Bioconjugate Chemistry, 26(8), 1533-1541.

56. Delgado, E., Bahal, R., Yang, J., Lee, J. M., Ly, H., \& PS Monga, S. (2014). $\beta$-Catenin knockdown in liver tumor cells by a Cell permeable gamma guanidine-based peptide nucleic acid. Current Cancer Drug Targets, 13(8), 867-878.

57. Posch, W., \& Piper, S. (2012). Inhibition of human immunodeficiency virus replication by cell membrane-crossing oligomers. Molecular Medicine, 18(1), 1.

58. Chin, J. Y., Kuan, J. Y., Lonkar, P. S., Krause, D. S., Seidman, M. M., Peterson, K. R., et al. (2008). Correction of a splice-site mutation in the beta-globin gene stimulated by triplex-forming peptide nucleic acids. Proceedings of the National Academy of Sciences, 105(36), 13514-13519.

59. Wright, D. G., Zhang, Y., \& Murphy, J. R. (2008). Effective delivery of antisense peptide nucleic acid oligomers into cells by anthrax protective antigen. Biochemical and Biophysical Research Communications, 376(1), 200-205.

60. Green, D. W., Roh, H., Pippin, J. A., \& Drebin, J. A. (2001). $\beta$-catenin antisense treatment decreases $\beta$-catenin expression and tumor growth rate in colon carcinoma xenografts. Journal of Surgical Research, 101(1), 16-20.

61. Wang, Z., Li, B., Zhou, L., Yu, S., Su, Z., Song, J., et al. (2016). Prodigiosin inhibits Wnt/ $\beta$-catenin signaling and exerts anticancer activity in breast cancer cells. Proceedings of the National Academy of Sciences, 113(46), 13150-13155.

62. Ganesh, S., Koser, M. L., Cyr, W. A., Chopda, G. R., Tao, J., Shui, $X$., et al. (2016). Direct pharmacological inhibition of $\beta$-catenin by rna interference in tumors of diverse origin. Molecular Cancer Therapeutics, 15(9), 2143-2154.

63. Kahn, M. (2014). Can we safely target the WNT pathway? Nature Reviews Drug Discovery, 13(7), 513-532. 